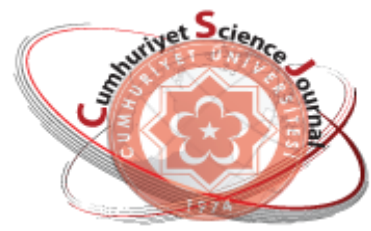

e-ISSN: 2587-246X

ISSN: $2587-2680$

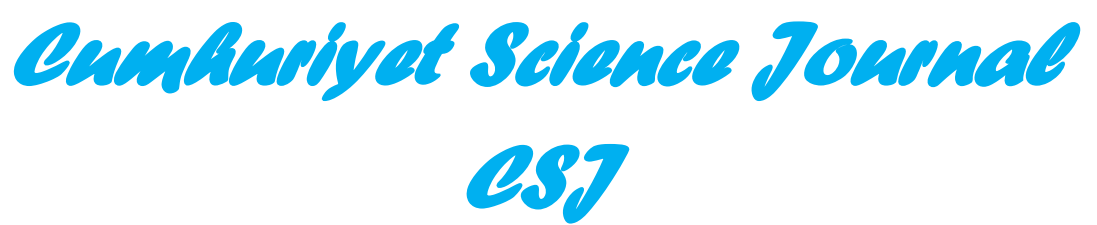

Cumhuriyet Sci. J., Vol.40-2(2019) 424-432

\title{
The Effect of Piranha and Silane Modifications on Boron Nitride Nanosheets (BNNSs) Thin Film Formation
}

\author{
Duygu KURU ${ }^{1}$ (D), Alev AKPINAR BORAZAN ${ }^{1, *}$ (D), Nuran AY' (D) \\ ${ }^{1}$ Bilecik Seyh Edebali University, Faculty of Engineering, Department of Chemical Engineering, Bilecik, TURKEY \\ ${ }^{2}$ Eskisehir Technical University, Faculty of Engineering, Department of Material Science and Engineering, \\ Eskisehir, TURKEY
}

Received: 04.02.2019; Accepted: 20.04.2019

http://dx.doi.org/10.17776/csj.521889

\begin{abstract}
In this study, the aim was to increase the adhesion between the two phases (glass substrate and BNNSs film). Surface treatment was provided by TEOS silane group and piranha solution. The retention times of the glass surfaces in the piranha solution and the adherence of different ratios of the silane solution to the glass surface were investigated. Surface characterization was carried out by Fourier Transform Infrared Spectrophotometer (FT-IR). Scanning Electron Microscopy (SEM) images were taken to characterize the surface morphology, the thickness of the thin films and the structure of boron nitride nanosheets. UV visible spectrophotometer was used to determine the efficiency of boron nitride nanosheets after the exfoliation process. Surface roughness tester (Time TR200) was used to determine surface roughness of the thin films. According to the results, it was observed that the piranha and silane solutions improved the adhesion of the glass surface. SEM images showed that the silane was coated on the glass surface and the coating material was retained on the silane. Excess silane loading caused the structure to deteriorate. Boron nitride yield was calculated and found to be $54.1 \%$ and $34.1 \%$ for different centrifugation rates after exfoliation.
\end{abstract}

Keywords: Boron Nitride Nanosheet, Surface Treatment, Dip-Coating, Thin Film

\section{Piranha ve Silan Modifikasyonlarının Bor Nitrür Nanosheets (BNNSs) İnce Film Oluşumu Üzerine Etkisi}

Özet. Bu çalışmada, iki faz arasındaki (cam alt tabaka ve BNNSs filmi) yapışmanın arttırılması amaçlanmıştır. Yüzey iyileştirmesi TEOS silan grubu ve piranha çözeltisi ile sağlanmıştır. Cam yüzeylerin piranha çözeltisinde tutunma süreleri ve silan çözeltisinin farklı oranlarının cam yüzeyine yapışması incelenmiştir. Yüzey karakterizasyonu Fourier Transform Infrared Spektrofotometre (FT-IR) ile yapılmıştır. Yüzey morfolojisini, ince filmlerin kalınlığını ve bor nitrür nanosheetlerin yapısını karakterize etmek için Taramalı Elektron Mikroskobu (SEM) görüntüleri alınmıştır. Eksfoliasyon işleminden sonra bor nitrür nanosheetlerin verimliliğgini belirlemek için UV görünür bölge spektrofotometresi kullanılmıştır. İnce filmlerin yüzey pürüzlülüğünü belirlemek için yüzey pürüzlülük cihazı (Time TR200) kullanılmıştır. Sonuçlara göre piranha ve silan çözeltilerinin cam yüzeyini yapışma için geliştirdiği görülmüştür. SEM görüntüleri silanın cam yüzeyinde kaplandığını ve kaplama malzemesinin silan üzerinde tutunduğunu göstermiş̧ir. Silan yüklemesinin fazla olması yapıda bozulmalara neden olmuştur. Eksfoliasyon sonrası farklı santrifüjleme hızları için bor nitrür verimi $\% 54,1$ ve $\% 34,1$ olarak hesaplanmıştır.

Anahtar Kelimeler: Bor Nitrür Nanotabaka, Yüzey Iyileştirme, Daldırarak Kaplama, Ince Film 


\section{INTRODUCTION}

Adhesion is one of the most important factors during the forma tion of a thin film. To increase adhesion between the two phases (glass substrate and film), the glass surface must be treated before coating. There are many surface treatments applied on glass such as hydrofluoric acid (HF) abrasion, $\mathrm{SnCl}_{2}$ sensitization, organic grading, sandblasting and sandpaper grinding. The etching technique using HF, a common reagent commonly used for glass treatment, causes the surface roughness to increase because of the physical treatment and promotes the formation of more silanol group $(\mathrm{SiOH})$ producing hexafluorosilicic acid $\left(\mathrm{H}_{2} \mathrm{SiF}_{6}\right)$. Another method is to sensitize the surface of the glass with a special treatment using $\mathrm{SnCl}_{2}$, which is a special treatment with a chemical conditioning process. This process is often used to change the nature of the glass chemical. Besides chemical processes, there is also a simple physical improvement that is commonly used. Silicon carbide ( $\mathrm{SiC})$ paper grinding is a method that continuously increases the surface area and surface roughness. This process increases the effective area of the Van der Waals force. As a result, these processes have a positive effect on the adherence of the material to the surface [1]. There are some studies on the improvement of the glass surface. In the study of Muanpho et al. glass surface was coated by gold nanoparticles to improve the surface. In this study, the glass surfaces were primarily ultrasonic cleaned for 15 minutes in ethanol and deionized water. Glass surfaces were then treated with hydrogen peroxide that has a volume ratio of 30:70 (30\%) and sulphuric acid (concentrated) for 60 minutes at $60-80^{\circ} \mathrm{C}$. Finally, the glass surfaces were washed with deionized water for 15 minutes and dried at $110^{\circ} \mathrm{C}$ for 45 minutes. After cleaning the surfaces, they used various silane groups (3-mercaptopropyltrimethoxy-silane (MPTMS), 3-aminopropyltrimethoxysilane (APTMS), polyethylenimine (PEI)) to modify the surface. Few gold nanoparticles were attached to the MPTMSmodified surface so that a homogeneous coating on the PEI-modified surface could be obtained. The first two silane groups reacted with the hydroxyl groups that were formed as a result of washing with piranha solution and formed the Si-O covalent bonds on the surface [2]. Nguyen et al. used 4 different methods for surface treatment in their study. They are Isopropyl alcohol treatment, 3\% $\mathrm{H}_{2} \mathrm{O}_{2}: \mathrm{H}_{2} \mathrm{SO}_{4}$ piranha solution for 30 minutes, oxygen plasma treatment, piranha solution and then treatment in ammonia plasma to increase amine positive functional groups. According to the result of the analysis, it was found that the amount of carbon on the surfaces treated with oxygen and ammonia plasma was significantly reduced compared to the other two methods [3]. In another study, Wang and Awadelkarim investigated the effect of the glass surface in order to obtain a polycrystalline silicon thin film transistor on the glass. Prior to coating, they treated the glass surface at $75^{\circ} \mathrm{C}$ in $\mathrm{NH}_{4} / \mathrm{H}_{2} \mathrm{O}_{2} / \mathrm{H}_{2} \mathrm{O}$ and $\mathrm{HCl} / \mathrm{H}_{2} \mathrm{O}_{2} / \mathrm{H}_{2} \mathrm{O}$ medium for 10 minutes. Surface treated and nontreated glass have a favorable effect on the surface properties of silicon-rich surface transistors on glass surface [4]. Pacaphol and Ong investigated the effect of silanes on interfacial adhesion and surface properties of nano-cellulose film coating on glass and aluminum surfaces. Silanes containing different functional groups were used to increase the adhesion of nanocellulose films on the glass and aluminum substrates and to increase their physical and mechanical properties. It has been found that the amino group-containing silane provides the best adhesion performance compared to epoxy and methacryloxy groups; higher proportions of amino silane tended to adhere better to glass and aluminum substrates. Furthermore, the amino silane has the ability to improve the surface hardness, elastic modulus and scratch resistance of the coating film [5]. In their study, Chitvoranund et al. investigated the adhesion effects of the silver film that is produced by electrolysis coating on the glass substrate. The glass surface was treated with three different methods: $\mathrm{HF}$ acid etching, $\mathrm{SnCl}_{2}$ activation, and silicon carbide paper milling. After this process, a glass slide was immersed in the coating solution for 90 minutes at room 
temperature. The HF pickling process has created pores on the surface. The size of the pores increased with increasing immersion time. On the other hand, the sensitivity that is provided by $\mathrm{SnCl}_{2}$ coating on the glass surface is similar to the untreated sample with a very smooth surface. The $\mathrm{SiC}$ paper grinding process made the surface smoother [1]. In their study in 2017, Ahmad et al. improved the glass surfaces with polyvinyl butyral (PVB). In order to strengthen the electro-optical properties of the R-PDLC, PVB was coated on the glass surface. It was mixed with $0.1 \%$ by weight of isopropyl alcohol to form the PVB layer and then distributed over the conductive surface of the ITO glass. After the first layer was dried, another PVB layer was produced on the first layer with the spin coating technique. According to the result of the analysis, they observed that PVB thin film improves the optical and hydrophobic properties of glass [6].

In our study, boron nitride nanosheets were produced by liquid exfoliation method, which is a high yield and low-cost process. There are several studies using this method to manufacture BNNSs with high efficiency [7-11]. Glass surfaces were kept in piranha solution at different time intervals and then modified with silane solution and surface improvement experiments were carried out.

\section{MATERIAL AND METHOD}

\subsection{Materials}

Nano-sized boron nitride powder (Bortek Boron Technologies and Mechatronics Ind. Co.) was used as the starting material to produce $2 \mathrm{D}$ boron nitride nanosheets. In the exfoliation method, isopropyl alcohol and distilled water (J.T. Baker) were used as a solvent. Materials used to improve surface cleaning and wettability are; ethanol (99\% purity, Sigma Aldrich), sulfuric acid $\left(\mathrm{H}_{2} \mathrm{SO}_{4}\right.$, Carlo Erba 96\%), hydrogen peroxide $\left(\mathrm{H}_{2} \mathrm{O}_{2}\right.$, Merck 35\%) and distilled water. Tetraethylorthosilicate (TEOS, ABCR GmbH 99\%) was used to increase the adhesion strength between the glass surface and the coated material. The $\mathrm{pH}$ of the solution was adjusted with acetic acid (Riedel de Haen, 100\%). Borosilicate microscope slides $(25.4 \times 76.2 \mathrm{~mm}$ in size and $1-1.2 \mathrm{~mm}$ in thickness) were used as the surface to be coated.

\subsection{Method}

\subsubsection{Production of Boron Nitride Nanosheets}

Boron nitride nanosheets were produced using sonication centrifugation technique. Low power ultrasonic bath was used to manufacture $2 \mathrm{D}$ boron nitride. In this method, the mixture of isopropyl alcohol and water were used as solvent. $0.2 \mathrm{~g}$ of bulk boron nitride powder was dispersed in $100 \mathrm{~mL}$ of solvent $(2 \mathrm{mg} / \mathrm{mL})$. The resulting mixture was sonicated in a $180 \mathrm{~W}$ ultrasonic bath for 3 hours at 45-minute intervals and centrifuged at 3200 and $4000 \mathrm{rpm}$ for 30 minutes to complete the formation of boron nitride nanosheet. The supernatant was placed in a new bottle.

\subsubsection{Surface treatment of glass substrates and thin film formation}

In the applied method, the glass surfaces were first washed ultrasonically in the ethanol solution for 15 minutes in order to remove impurities from the surface. Then, 3:1 $\mathrm{H}_{2} \mathrm{SO}_{4}: \mathrm{H}_{2} \mathrm{O}_{2}$ (sulphuric acid and hydrogen peroxide) solution, also called as piranha, was prepared and the cleaned glass surfaces were kept in piranha solution for different periods (10 minutes, 20 minutes, 30 minutes) to increase the wettability of the surface. The glass surfaces in piranha solution were washed with distilled water before being immersed in boron nitride nanosheet solution. $10 \%, 20 \%$ and $30 \%$ methanol solutions of the silane group (TEOS) were prepared and added to the solution at the same rate as the boron nitride concentration. To accelerate the hydrolysis and condensation reactions of the silane group, acetic acid was added dropwise to bring the $\mathrm{pH}$ of the solution to 4. Glass surfaces were immersed into the solution 5 times and kept in the solution for 5 minutes. After immersion, the glass surfaces were dried for 1 day in room conditions to remove the excess solvent and other volatile components on the glass. The dried glasses were treated in a tube oven at $550^{\circ} \mathrm{C}$ for 5 hours in the presence of nitrogen gas. The experimental conditions were given in Table 1. 
Table 1. Experimental conditions for surface treatment

\begin{tabular}{llll}
\hline Sample codes & $\begin{array}{l}\text { Solution } \\
(\mathrm{mg} / \mathrm{mL})\end{array}$ & $\begin{array}{l}\text { concentration } \\
\text { Time (minutes) }\end{array}$ & $\begin{array}{l}\text { Piranha Solution Holding } \\
(\%)\end{array}$ \\
\hline BNP10 & 2 & 10 & - \\
BNP20 & 2 & 20 & - \\
BNP30 & 2 & 30 & - \\
BNP30S10 & 2 & 30 & 10 \\
BNP30S20 & 2 & 30 & 20 \\
BNP30S30 & 2 & 30 & 30 \\
\hline
\end{tabular}

\subsection{Characterization}

In order to determine the morphological characteristics of the surface images of thin films and boron nitride nanosheets, SEM (Zeiss Supra 40VP, Germany) analysis was performed. Images were taken from the surface and surface section at different magnifications. The presence of boron nitride and silane groups on the coating surface was investigated by FT-IR (Agilent Technologies, Cary 630) analysis with $400-4000 \mathrm{~cm}^{-1}$ wavelength range. The amount of boron nitride nanosheet formed in the liquid exfoliation method was determined by UV-visible region spectroscopy (Agilent Technologies, Cary $60 \mathrm{Uv}$-Vis). The surface roughness of the thin films was obtained using surface roughness tester (Time TR200).

\section{RESULTS AND DISCUSSION}

\subsection{SEM Images of Boron Nitride Nanosheets}

Figure 1 contains SEM images at 3200 and 4000 rpm of boron nitride nanosheet in which the mixture of isopropyl alcohol and water are used as solution. The surface was covered with platinum before the SEM analysis. Figure 1-b shows that the lateral dimensions of nanosheets range from 100 to $300 \mathrm{~nm}$. Since nano-sized bulk h-BN powder has been used in the exfoliation process, obtained nanosheets were thick (about $20 \mathrm{~nm}$ ). In SEM images at $4000 \mathrm{rpm}$ (Figure 1-d), thinner nanosheets were formed. The separation of the boron nitride layers can be improved by increasing the rate of centrifugation [8]. Since the synthesis is done at low speed, nanosheets are seen in a stacked form.

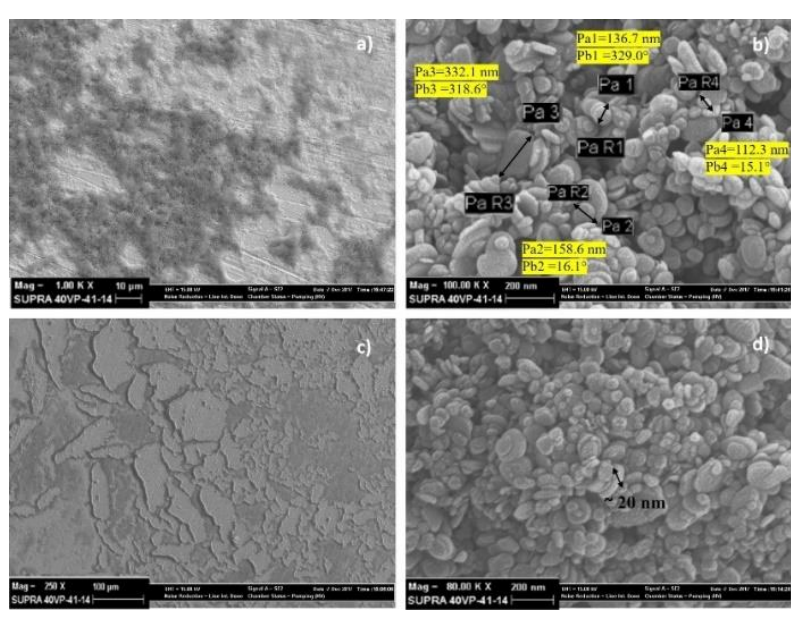

Figure 1. SEM images of boron nitride nanosheets at different centrifugal speeds and magnifications a) $3200 \mathrm{rpm}, 1.00 \mathrm{X} \mathrm{b)} 3200 \mathrm{rpm}, 100.00 \mathrm{X}$ c) 4000 rpm, 250X d) $4000 \mathrm{rpm}, 80.00 \mathrm{X}$

\subsection{SEM Images of Surface-Treated Thin Films}

SEM images of coated surfaces using different piranha immersion times were given in Figure 2. Figure 2- a,b shows the images in different magnifications of the coatings obtained by immersing the glass surfaces in a solution of piranha for 10 minutes. When the SEM images are examined, it is observed that there is not much adhesion to the surface, but in some cases, the acid etching increases the area of contact of the coating with the surface. To increase the area of contact of the piranha solution with the surface and to facilitate the adhesion of the coated solution to the glass surface, the waiting time in the piranha was increased to 20 minutes. Figure 2-c, d shows the images of the coatings obtained by immersing the glass surfaces in piranha solution for 20 minutes. It 
is observed that a denser part is attached to the glass surface, although not homogeneous, compared to the BNP10 sample. As the contact time with acid increased, the area occupied by the attachment increased. The coated material was stacked on the surface. In a study conducted by Chitvoranund et al. in 2013, it was determined that when the glass surfaces were eroded with acid in different time periods such as 60, 90 and 120 seconds, the pores on the surface at the end of 120 seconds were discovered to be larger than other durations. The surface before the etching was smooth and after the acid treatment, eroded and porous surfaces were obtained [1]. Figure 2-e, $\mathrm{f}$ is a view of the glass surfaces obtained by immersing them in a solution of piranha for 30 minutes. The images show a more homogeneous spread compared to the surfaces after 10 and 20 minutes. The surface roughness and consequently the surface area has increased, thus resulting in a better film adhesion. Waiting for glass surfaces in the piranha solution for 30 minutes increased the area where Van der Waals forces were effective and widened the surface area of boron nitride particles.
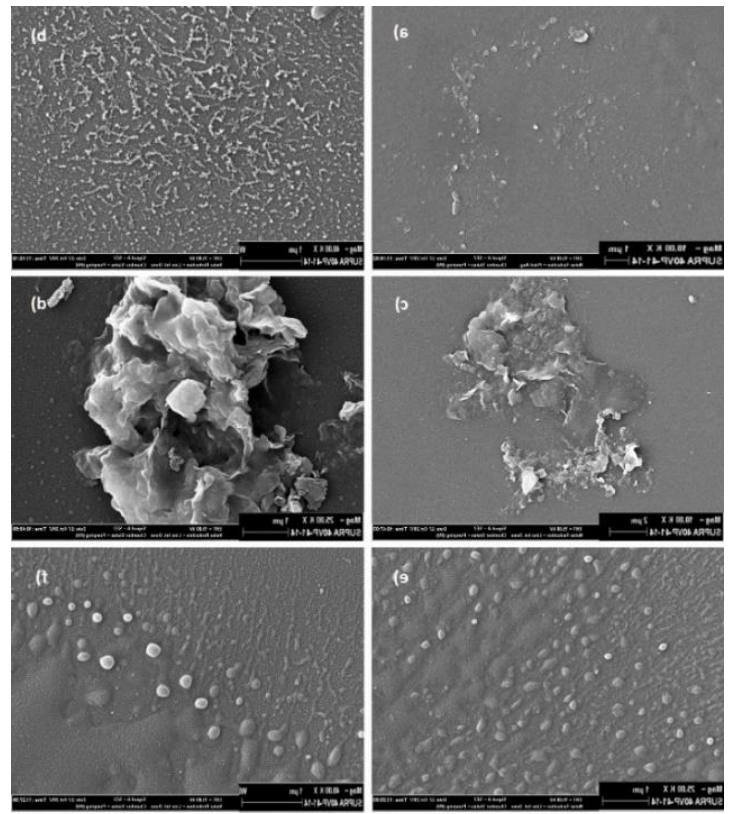

Figure 2. SEM images of coated surfaces of different piranha immersion times a,b )10 mins, b,c) 20 mins, d,e) 30 mins

Figure 3 shows the SEM images of glass surfaces modified with silane and piranha solution. In Figure 3-a, $b$ the images of the surfaces obtained by immersing the glass surfaces in piranha solution for
30 minutes and then dipping them into a $10 \%$ silane and a boron nitride nanosheet solution were given. The addition of silane groups only improved the adhesion between the material and the surface that consisted of the coatings made with piranha, which allowed more materials to adhere to the surface. It is well known that silane groups have a very active structure on glass surfaces. They also act as a binding agent between organic and inorganic materials. Silanol groups ( $\mathrm{Si}^{-} \mathrm{OH}$ ) occur in the hydrolysis event after the contact of the alkoxy groups in the structure of the silane with water. These silanol groups react with the hydroxyl groups in the condensation step to form a crosslinked silane layer between the adjacent silane molecules. As a result of these reactions, the surface of the glass is activated, and the coating material is improved by the surface [12]. In Figure $3-\mathrm{a}, \mathrm{b}$ it is observed that the adhesion between the glass surface and the material increased by $10 \%$ after the silane improvement, compared to the coating without silane. Figure $3-c, d$ exhibit the SEM images of the coatings obtained by immersing the glass surfaces in piranha solution for 30 minutes. From the SEM images, it is evident that the film becomes continues as the silane amount was increased. In a study conducted by Cecchin et al. in 2016, similar SEM images were obtained by coating the glass fibers that are used for surface treatment with silane groups. The acid they use, which is HF, increases the wetting properties of the surface by increasing the energy on the surface of the glass fibers [13]. The cross-sectional images and thickness of the BNP30S20 sample were also given. The thickness of the resulting film was $42.774 \mu \mathrm{m}$.

In Figure 3-e, f shows the SEM images of BNP30S30 film, which was prepared by pretreating the glass surfaces in piranha solution for 30 minutes and subsequently in a mixture of $30 \%$ silane solution. The coating material, which is intended to adhere to the surface, was deposited on the silane group. It is also seen that the silane group that is coated on the glass surface is partially fragmented. It is thought that this degradation occurs after hydrolysis and condensation reactions of TEOS. The average thickness of the thin film coating is $37.25 \mu \mathrm{m}$. According to the images, it 
was observed that a double layer coating was formed. The boron nitride particles were coated on the silane. In order to form a boron nitride coating as a single surface, silane groups must be removed from the surface.
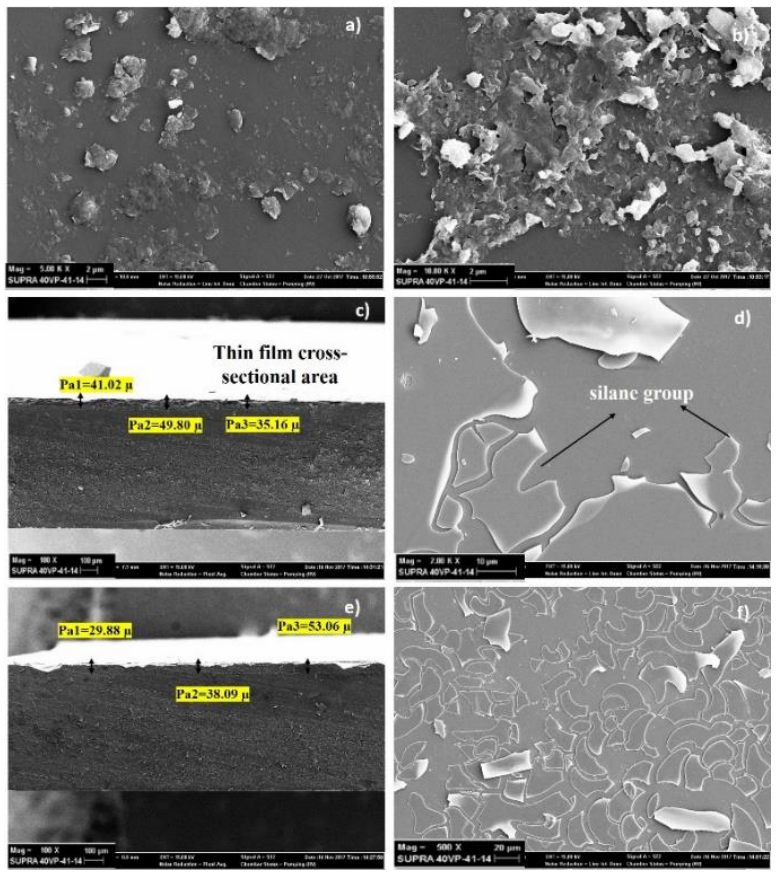

Figure 3. SEM images of coated surfaces kept in piranha solution for 30 minutes and for different silane concentrations a,b) $10 \%, \mathrm{~b}, \mathrm{c}) 20 \%$, d,e) $30 \%$.

\subsection{Raman Spectroscopy Analysis Fourier Transformed Infrared Spectrophotometer (FT-IR) Analysis Results}

FT-IR analyzes were performed in the wavelength range of $400-4000 \mathrm{~cm}^{-1}$. Figure 4 shows the IR spectrum of the uncoated glass slide. Figure 5 and 6 shows the IR spectrum of the thin films obtained after the surface treatment. Figure 5 shows the IR spectra of thin films obtained by immersing glass surfaces in piranha solution for different time intervals. Stretching band appeared at $2949.93 \mathrm{~cm}^{-}$ ${ }^{1}$ wavelength is related to asymmetric $\mathrm{C}-\mathrm{H}$ strain. This band is belonging to the $\mathrm{CH}_{3}$ group in the methanol structure used in all solutions. The stretching band around 2106.05 (Figure 5 and 6) shows NCO groups.

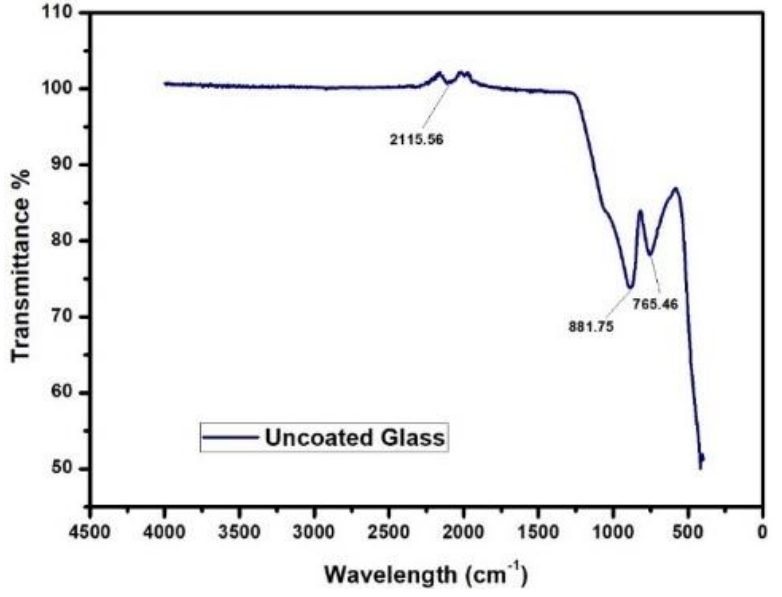

Figure 4. IR spectrum of uncoated glass slide

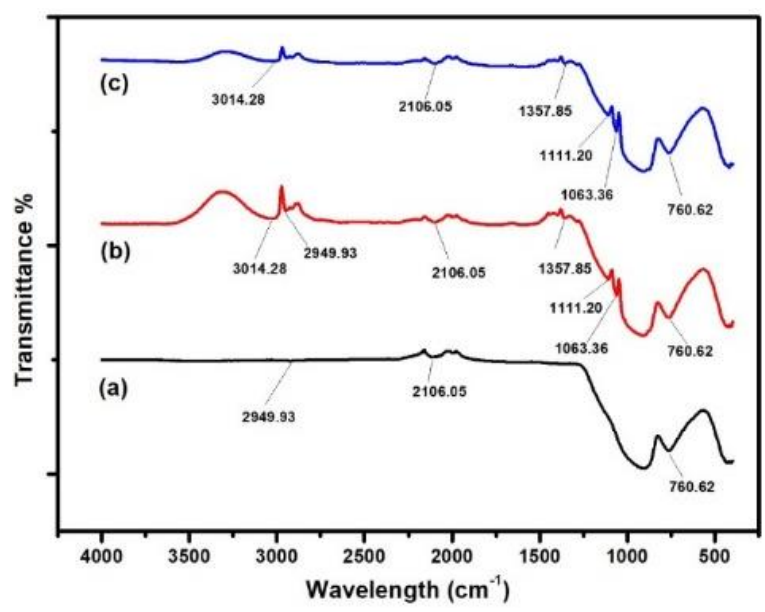

Figure 5. IR spectrum of thin films obtained as a result of surface improvement a) BNP10 b) BNP20 c) BNP30

The stretching around the wavelength of 1357.85 $\mathrm{cm}^{-1}$ represents the $\mathrm{CH}_{2}$ and $\mathrm{CH}_{3}$ groups in methanol or ethanol. Similar stretching was observed in the coatings on the surfaces which were kept in piranha solution for 20 minutes and 30 minutes while some $\mathrm{CH}_{2}-\mathrm{CH}_{3}$ stretching was not observed in the coating held in solution for 10 minutes. The stretching of $1111.20 \mathrm{~cm}^{-1}$ and 1063.36 belong to the $\mathrm{C}-\mathrm{O}$ asymmetric band. The band at $760.62 \mathrm{~cm}^{-1}$ in all samples (Figure 4,5,6) refers to the oxygen-induced $\mathrm{Si}-\mathrm{O}$ or $\mathrm{Si}-\mathrm{O}-\mathrm{Si}$ bonding of the silicon present in the glass structure [14]. In the coating spectrum of the solution prepared with $30 \%$ silane (Figure 6), the band at $1357.85 \mathrm{~cm}^{-1}$ was considered to belong to $\mathrm{CH}_{3}$ groups in TEOS. The strain of $1007.26 \mathrm{~cm}^{-1}$ occurring in the $30 \%$ sample also shows C-O binding. The stretching band at $911.57 \mathrm{~cm}^{-1}$ in all 
the samples (a), (b) and (c) refers to non-bridged fractured $\mathrm{Si}-\mathrm{O}$ bonds. This stretch is thought to be due to the formation of Si-O covalent bond on the surface by reacting with the hydroxyl groups resulting from washing with the piranha solution of the silane group [2].

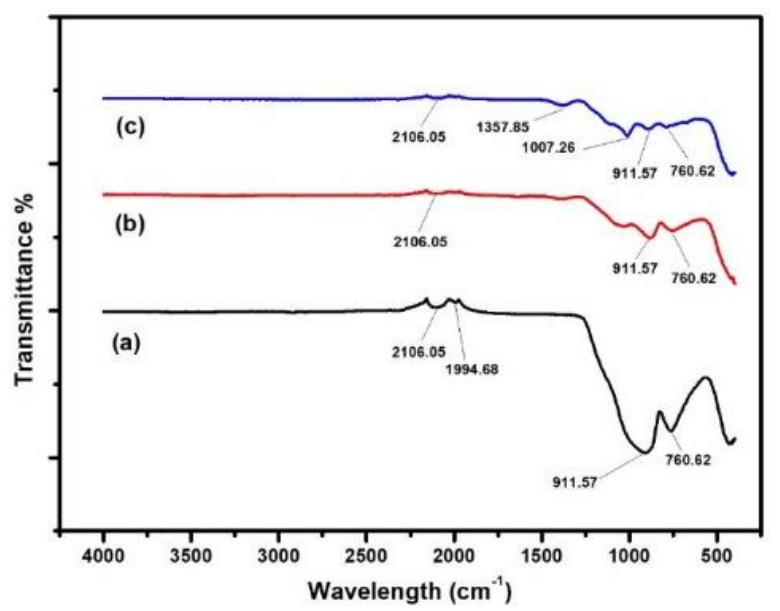

Figure 6. IR spectrum of thin films obtained as a result of surface improvement a) BNP30S10 b) BNP30S20, and c) BNP30S30

\subsection{Determination of Boron Nitride Nanosheets Concentration}

UV-Visible Spectrophotometer was used for the quantification of the obtained nanosheets. At 400 $\mathrm{nm}$ wavelength [15]. $2 \mathrm{ppm}(2 \mathrm{mg} / \mathrm{mL})$ suspension was prepared by diluting the mixture with isopropyl alcohol and water. Table 2 shows the absorbance values of the suspensions prepared in various ppm values.

Table 2. Absorbance values of suspensions prepared in different concentrations

\begin{tabular}{ll}
\hline Concentration $(\mathrm{ppm})$ & Absorbance \\
\hline 0.5 & 3.1554 \\
1 & 3.3420 \\
1.5 & 3.5173 \\
2 & 3.6857 \\
BNNSs solution $(3200 \mathrm{rpm})$ & 3.2246 \\
BNNSs solution $(4000 \mathrm{rpm})$ & 3.3658 \\
\hline
\end{tabular}

A calibration curve was drawn according to the obtained data and the linear equation was created. The absorbance value of the boron nitride nanosheet suspension that is prepared at 3200 and $4000 \mathrm{rpm}$ was calculated from this equation and the concentration value was determined to be 1.082 ppm and $0.6823 \mathrm{ppm}(\mathrm{mg} / \mathrm{mL})$ respectively. Sonication yield was calculated as $54.1 \%$ and 34.1 $\%$ starting from the initial amount $(2 \mathrm{mg} / \mathrm{mL})$. The peeling of the nanoparticles in the solvent is due to the strong interaction between the solvent and the nanoparticles; this means that there is little energy for exfoliation. During sonication of the boron nitride flasks in the solvent, initially large flakes are separated into smaller flakes and a greater amount of energy is obtained as the duration and rate of centrifugation increases and a small number of layers or a high concentration of nanosheets is obtained. For this reason, to perform an efficient exfoliation, the solvent should be dispersive, polar, and have H-bonding solubility parameters matching those of layered materials in order to minimize the exfoliation energy to ensure effective exfoliation [16].

\subsection{Surface Roughness of BNNSs Thin Films}

Roughness is the length of many scratched, irregular short wavelengths that occurs when a hand tool moves from one end of the surface to the other. One of the parameters used to determine the surface roughness is the arithmetic mean deviation (Ra) value and results in $\mu \mathrm{m}$. This expression has been described as the average height of the central axis in the BSJ standard. Surface roughness measurement devices can be read directly. The surface roughness values of thin films prepared at different conditions were given in Table 3. It was observed that the surface roughness ranged between 0.03 and $0.14 \mu \mathrm{m}$. From the results, it can be concluded that roughness values increased as the surface etching increased (Figure 2).

Table 3. The surface roughness of BNNSs thin films

\begin{tabular}{ll}
\hline Sample codes & Roughness $(\mathrm{Ra}, \mu \mathrm{m})$ \\
BNP10 & 0.030 \\
BNP20 & 0.044 \\
BNP30 & 0.049 \\
BNP30S10 & 0.115 \\
BNP30S20 & 0.129 \\
BNP30S30 & 0.140 \\
\hline
\end{tabular}

The surface became increasingly porous and irregular because of the dissolution of the glass phase after piranha and silane modifications. 
Therefore, voids and channels become larger and deeper as the etching time and silane concentration increases [17-19].

\section{CONCLUSION}

In general, modifications of piranha and silane group showed a positive effect on adhesion of boron nitride nanosheets to the glass surface. As the waiting time of glass surfaces in the piranha solution increased, the adhesion of the boron nitride nanosheet to the surface increased. Keeping glass surfaces in the piranha solution for 30 minutes increased the effective area of the Van der Waals forces and widened the surface area of boron nitride particles. It is also seen that the silane group coated on the glass surface is partially fragmented when the loading of the silane group is $20 \%$ and $30 \%$. In IR spectrum of the thin films treated with silane groups, non-bridged fractured $\mathrm{Si}-\mathrm{O}$ bonds were observed. This stretch is thought to be due to the formation of Si-O covalent bonds on the surface by reacting with the hydroxyl groups resulting from washing with the piranha solution of the silane group. Sonication yield was calculated as $54.1 \%$ and $34.1 \%$ for boron nitride nanosheets. According to the results if less than $20 \%$ silane group is used, surface defects can be eliminated.

\section{ACKNOWLEDGEMENTS}

We would like to thank Bilecik Şeyh Edebali University Scientific Research Projects Unit, who supported our work with the project of 2017-01. BŞEÜ.03-07.

\section{REFERENCES}

[1] Chitvoranund N., Jiemsirilers S., Kashima D.P., Effects of surface treatments on adhesion of silver film on glass substrate fabricated by electroless plating, J. Aust. Ceram. Soc., 49 (2013) 62-69.

[2] Muanpho K., Praserthdam P., Pavarajarn V., Surface Modification for fabrication of gold nanoparticles thin film on glass substrate, In: 4th Thailand Materials Science and Technology Conference; 31 March-1 April (2006) Bangkok, Thailand.
[3] Nguyen C.V., Bartali R., Crema L., Speranza G., Effect of glass surface treatments on the deposition of highlytransparent reduced graphene oxide films by dropcasting method, Colloid Surface A, 498 (2016) 231-238.

[4] Wang Y.Z. and Awadelkarim O.O., The Effects of Glass-Substrate's SurfaceTreatment on the Characteristics of $\mathrm{N}$ Channel Polycrystalline Silicon Thin Film Transistors, J. Electron. Mater., 27 (1998) 77 80.

[5] Pacaphol K. and Aht-Ong D., The influences of silanes on interfacial adhesion and surface properties of nanocellulose film coating on glass and aluminum substrates, Surf\&Coat. Tech., 320 (2017) 70-81.

[6] Ahmad F., Jamil M., Jeon Y.J., Alteration of glass surface via polyvinyl butyral (PVB) layer for reverse mode polymer dispersed liquid crystal (R-PDLC) display, Phase Transit., 90 (2017) 873-881.

[7] Wang Z., Tang Z., Xue Q., Huang Y., Huang Y., Zhu M., Pei Z., Li H., Jiang H., Fu C., Zhi C., Fabrication of Boron Nitride Nanosheets by Exfoliation, Chem. Rec., 16 (2016) 12041215.

[8] Li X., Hao X., Zhao M., Wu Y., Yang J., Tian Y., Qian G., Exfoliation of hexagonal boron nitride by molten hydroxides, Adv. Mater., 25 (2013) 2200-2204.

[9] Wang Y., Shi Z., Yin J., Boron nitride nanosheets: large-scale exfoliation in methanesulfonic acid and their composites with polybenzimidazole, J. Mater. Chem., 21 (2011) 11371-11377.

[10] Zhi B.C., Bando Y., Tang C., Kuwahara H., Golberg D., Large-Scale Fabrication of Boron Nitride Nanosheets and Their Utilization in Polymeric Composites with Improved Thermal and Mechanical Properties, Adv. Mater., 21 (2009) 2889-2893.

[11] Liu J., Kutty R.G., Zheng Q., Eswariah V., Sreejith S., Liu Z., Hexagonal Boron Nitride Nanosheets as High-Performance Binder-Free Fire-Resistant Wood Coatings, Small, 13 (2016) 1602456.

[12] Dvir H. and Gottlieb M., Effect of Silane Sizing on Polymer-Glass Adhesion, Am. 
Phys. Soc., (2007) APS March Meeting; March 5-9,2007; Denver, Colorado.

[13] Cecchin D., Farina A.P., Vitti R.P., Moraes R.R., Bacchi A., Spazzin A.O., Acid Etching and Surface Coating of Glass-Fiber Posts: Bond Strength and Interface Analysis, Braz. Dent. J., 27 (2016) 228-233.

[14] Rubio F., Rubio J., Oteo J.L., A FT-IR Study of the Hydrolysis of Tetraethylortho silicate(TEOS), Spectrosc. Lett., 31 (2013) 199-219.

[15] Marsh K.L., Souliman M., Kaner R.B., Cosolvent exfoliation and suspension of hexagonal boron nitride, Chem. Commun., 51 (2015) 187-190.

[16] Durge R., Kshirsagar R.V., Tambe P., Effect of sonication energy on the yield of graphene nanosheets by liquid-phase exfoliation of graphite, Procedia Engineer, 97 (2014) 14571465.

[17] Smielak B. and Klimek L., Effect of hydrofluoric acid concentration and etching duration on select surface roughness parameters for zirconia, J. Prosthet. Dent., 113 (2015) 596-602.

[18] Affatigato M., Osborne D.H., Haglund R.F., Effect of Surface Roughness on the Acid Etching of Amorphous Silica, J. Am. Ceram. Soc., 79 (1996) 688-694.

[19] Zogheib L.V., Della Bona A., Kimpara E.T., Mccabe J.F., Effect of Hydrofluoric Acid Etching Duration on the Roughness and Flexural Strength of a Lithium DisilicateBased Glass Ceramic, Braz. Dent. J., 22 (2011) 45-50. 